\title{
Elephant Losses in Uganda - and Some Gains
}

\author{
Robert Malpas
}

In the eight years of Idi Amin's rule, law enforcement in the national parks and reserves completely collapsed, and poaching and human encroachment increased. Last year, Robert Malpas, working for the New York Zoological Society and World Wildlife Fund/IUCN, and with some help from ffPS, spent nine months on a survey of Uganda's national parks and reserves to determine just how bad the situation really was. He found the elephant situation so desperate in both the Rwenzori and Kabalega Falls National Parks, except in one area, that there is no certainty of their survival in either even if the poaching can be controlled.

The breakdown of law and order in Uganda, coupled with a sixfold increase in human population since the turn of the century, has had a devastating effect on Uganda's wildlife. Increasing human density around the protected areas has brought agricultural and pastoral encroachment and increased poaching in parks and reserves.

A roll-call of the major catastrophes paints a very bleak picture indeed: the rare northern white rhino Ceratotherium simum cottoni has been wiped out in its stronghold in the Ajai Game Reserve in the West Nile district, and almost certainly also from the Kabalega Falls National Park, where 21 were translocated between 1961 and 1964 (see Oryx 6, 184-9). In both Kabalega and the Kidepo Valley National Park in north-east Uganda the black rhino Diceros bicornis is not far behind the white rhino on the road to extermination. In the Rwenzori National Park, only 153 elephants remain where seven years ago there were almost $3000 .{ }^{1}$ In Kabalega Falls National Park south of the Nile, their plight is even grimmer: the once magnificent north Bunyoro elephant population, estimated in 1973 at almost $10,000,{ }^{3}$ has been decimated. In March 1980 Dr Iain Douglas-Hamilton, Chairman of the IUCN African Elephant Group, and I could locate only 172 elephants from the air, and heavy poaching since is likely to have reduced them still further.

Other large mammals are faring little better. In both Kabalega Falls and Rwenzori Parks buffalo are under intensive pressure from meat poachers, and numbers have fallen dramatically over the past decade - in Rwenzori from 18,000 in $1969^{4}$ to just 4200 , a reduction of around 75 per cent; in Kabalega from 14,000 in $1967^{5}$ to 6400 , a 55 per cent reduction. In the Ishasha region of Rwenzori the isolated topi Damaliscus lunatus jimela population is down to just 20 per cent of its 1973 level. ${ }^{9}$ In the Toro Game Reserve, on the shores of Lake Albert, Jackson's hartebeest Alcelaphus buselaphus jacksoni has disappeared, and buffalo, Uganda kob Kobus kob thomasi and defassa waterbuck K. defassa are all greatly diminished in number. In the Kigezi Gorilla Reserve, widespread incursions by cultivators, woodcutters and poachers are threatening the mountain gorilla Gorilla g. beringei in Uganda's section of the Virunga volcanoes. The Lake Mburo Game Reserve has been invaded by cattle herders with upwards of 10,000 Ankole cattle. 
A chronicle of disasters. But is all the news bad, or is there still hope for Uganda's once magnificent wildlife reserves? For the elephants in Rwenzori and Kabalega south of the Nile the future is certainly bleak. In the Rwenzori aerial survey we saw 241 elephants carcasses, of which 25 (16.3 per cent of the live population) were estimated to have died within the previous six months. ${ }^{1}$ One hope was that some might have sought refuge in the Maramagambo Forest or other contiguous forest areas, but foot safaris in areas of the forest where only a few years ago they had been active revealed little or no sign of them.

In Kabalega south of the Nile only one large herd of 162 (Herd Z), plus three small groups totalling 10 individuals, could be located. Herd $\mathrm{Z}$ was constantly on the move and left a highly visible trail in the long grass. As our aircraft approached, the herd, which seemed to have no young calves, began running and appeared panic-stricken. Following a short distance behind them and evidently unable to keep up were several elephants that had clearly been wounded and would probably die. Further back along the trail we spotted a number of freshly dead elephants.

Of the elephant carcasses seen on the aerial survey of Kabalega Falls National Park which were estimated to have died within the previous twelve months (Categories 1 and 2 of Douglas-Hamilton and Hillman, 1979), 121 were seen in Kabalega South of the Nile; this represents 71 per cent of the live elephants there. Many of the carcasses were in groups sometimes of ten or more individuals, which we later discovered was the result of the poachers' use of automatic weapons. No meat had been cut off any of the poached elephants; they were killed solely for their ivory.

The ratio of dead to live elephants in Rwenzori and Kabalega South is a clear warning that, unless these current trends are arrested, the surviving elephants could be wiped out in a matter of months. Drastic anti-poaching measures are needed to save them, but even with such measures their long-term survival is certainly not assured. The heavy poaching has disrupted their social organisation, and both ground and air observations of herd structure show that recruitment is negligible at present. The hope is that births will increase once the herds are stringently protected from poachers.

Fortunately, not all Uganda's wildlife is in such a precarious state as this. In Kabalega north of the Nile, for example, there are about 1250 elephants which are in no immediate danger. More significant, the count results for the past five years suggest that in this area the elephant decline has halted, no doubt due to less poaching in the north of the park, which in turn can be attributed to the presence of park headquarters, tourist lodges and a developed road network. Nevertheless, Figure 2 shows that ivory poachers are very active on this bank of the Nile.

In Rwenzori the hippo population is still a sizeable one, numbering some 3000 , though poaching has reduced it to a third of its size seven years ago. ${ }^{2}$ Furthermore, there are an estimated 25,000 hippo in the neighbouring Virunga National Park in Zaire, some of which may well migrate into Rwenzori once the poaching is curbed. Uganda kob also appear to have weathered the intense poaching of recent years; the survey results show an increase in both parks: in Rwenzori from 11,500 in $1972^{7}$ to 19,800 , in Kabalega South from 2,600 in $1967^{3}$ to 10,400 , attributable no doubt to the kob's shy disposition, a defensive device which makes it a very difficult animal for poachers to approach closely. 
There are several reasons for optimism for the buffalo populations once the poaching is curbed. First, despite the massive reduction, buffalo are still widespread in both parks, and secondly, ground observations show a high proportion of calves, which suggests that the buffalo have not suffered a disruption of their social organisation of the kind noticed in the elephant populations. Finally, historical precedents give grounds for some optimism. In the Serengeti National Park, in Tanzania, following a large-scale die-off from rinderpest, the buffalo population rose from c.27,000 in 1958 to over 61,000 in $1970,{ }^{8}$ and in western Uganda buffalo have recovered from similar catastrophic declines in the last century.

Uganda's economic problems make it difficult to plan and carry out an effective programme for the rehabilitation of the national parks and reserves. Nevertheless, some immediate action is needed to regain control and stop the downward slide in wildlife numbers. The first priority is obviously to suppress poaching, and it is encouraging that the United Nations Development Programme has plans to revitalise the anti-poaching ranger forces in the national parks. The second priority is to re-establish reserve and national park boundaries and remove all encroaching human settlement. At present encroachment is not a serious problem in the Rwenzori and Kabalega Falls parks, but several game reserves, in particular Kigezi, Lake Mburo and the Kibale Forest Corridor, have been invaded by cultivators and pastoralists.

The Ugandan people are at present recovering from (some would say still weathering) a very difficult period. They face numerous day-to-day problems, not least lack of food. It is difficult for outsiders to understand the scale of these hardships, but they should realise that the ordinary Ugandan does not, at present, put wildlife preservation high on his list of priorities. To some extent, however, this is due to a lack of knowledge of the disastrous state of affairs in the conservation areas. Most Ugandans know nothing of the massive decline in wildlife numbers, and would be very surprised to learn that their once magnificent herds of elephant are now on the verge of extinction. As the results of this survey become known within Uganda, it is encouraging to find that government and individuals alike show great concern, and a desire to arrest the downward slide.

A case in point is the Kigezi Gorilla Reserve, where as much as 10 per cent of the reserve area is believed to have been lost to agricultural encroachment in recent years, with the result that the mountain gorilla rarely uses the Uganda side of the Virunga volcanoes. This problem is being tackled.

A ground and aerial survey of the reserve will soon be made to locate the problem areas and assess what action should be taken, after which the reserve boundaries will be demarcated - a necessary preliminary to an effective evacuation programme. Hopefully, settlers will be removed within the year. For the long term, there is a move to get the reserve, among others, gazetted a national park, an essential step if the gorilla's habitat is to be truly safeguarded.

The Kigezi operation will, it is hoped, be the first of a series of positive conservation measures which will reverse the negative trend in wildlife conservation since Amin came to power. The task of rehabilitating the national parks and reserves is immense. With the lack of expertise and foreign exchange Uganda cannot hope to tackle the problems alone, and help is desperately needed from the international conservation community. But others beside myself who have visited the parks and reserves recently are convinced that the 
potential of these areas is still immense and that no effort should be spared to help them achieve their former pre-eminence. The problems are daunting, but far from insurmountable.

\section{Acknowledgments}

The work described was carried out at the invitation of the Uganda Ministry of Tourism and Wildlife, whose cooperation is gratefully acknowledged. The survey was sponsored by the New York Zoological Society and WWF/IUCN, with additional support from the Frankfurt Zoological Society, the African Wildlife Leadership Foundation and the Fauna and Flora Preservation Society. Uganda National Parks provided aviation fuel and subsistence expenses during the aerial survey and much practical assistance.

\section{References}

1. DOUGLAS-HAMILTON, I., and A.K.K. HILLMAN 1979. Elephant carcasses and skeletons as indicators of population trends. International Workshop on Aerial Survey Methods, ILCA. In press.

2. ELTRINGHAM, S.K. 1973. The large mammal community of the Queen Elizabeth National Park (Uganda). Ann. Univ. Abidjan, Ser. E (Ecologie) 6: 189-219.

3. ELTRINGHAM, S.K., and R.C. MALPAS 1980. The decline in elephant numbers in Rwenzori and Kabalega Falls National Parks, Uganda. Afr. F. Ecol. 18: 73-86.

4. ELTRINGHAM, S.K., and M.H. WOODFORD 1973. The numbers and distribution of buffalo in the Ruwenzori National Park, Uganda. E. Afr. Wildl. $\mathcal{f}$. 11: $151-64$.

5. LAWS, R.M., I.S.C. PARKER and R.C.B. JOHNSTONE 1975. Elephants and their habitats. Clarendon Press, Oxford.

6. MALPAS, R.C. 1978. The ecology of the African elephant in Rwenzori and Kabalega Falls National Parks, Uganda. Ph.D. thesis, University of Cambridge.

7. MODHA, K.L., and S.K. ELTRINGHAM 1976. Population ecology of the Uganda kob (Adenota kob thomasi Neumann) in relation to the territorial system in the Rwenzori National Park, Uganda.F. Appl. Ecol. 13: 453-73.

8. SINCLAIR, A.R.E. 1977. The African Buffalo. University of Chicago Press.

9. YOACIEL, S.M., and K.G. van ORSDOL 1980. The influence of environmental changes on an isolated topi (Damaliscus lunatus jimela Matschie) population in the Ishasha Sector of Rwenzori National Park, Uganda. Afr. F. Ecol. 18. In press.

Dr R. C. Malpas, Embassy House, Harambee Avenue, PO Box 48177, Nairobi, Kenya.

\section{Black Muntjac Discovery}

The black muntjac Muntiacus crinifrons, one of the larger muntjacs, is a rare native of China. Until 1964 only three specimens were known to western science: a male was sent alive to London Zoo in 1885; the skin of an adult female was sent to the British Museum in 1886, and a male was taken by an American expedition in 1920. But in 1964 a Chinese expedition investigating fur-bearing resources found black muntjac on Mount Huaiyuan, in Jiangxi province; and in 1972 they were found in several areas in Anhui province. At first, say Sheng Helim and Lu Hogee, writing in the Fournal of Natural History, 'we were surprised to find the black muntjac inhabiting all suitable places in luxuriant mountainous forest in high altitudes in East China'. The area ranges from $28^{\circ}$ to $31^{\circ} \mathrm{N}$ and from $117^{\circ}$ to $120^{\circ} \mathrm{E}$, where the climate is warm and humid with sub-tropical monsoon conditions. The muntjac favour areas where the hillsides are steep, with sheer precipices and an altitude of $1000 \mathrm{~m}$. The vegetation is a mixture of deciduous broad-leaved forest, bamboo stands, evergreen and semi-evergreen forest; they also do well in secondary forest. Black muntjac are now known in 37 counties of four provinces: Anhui, Zhejiang, Jiangxi and Fujian. 